\title{
Effect of Asthma and PTSD on Persistence and Onset of Gastroesophageal Reflux Symptoms Among Adults Exposed to the September 11, 2001, Terrorist Attacks
}

\author{
Jiehui Li, MBBS, MSc, ${ }^{1 *}$ Robert M. Brackbill, PhD, MPH, ${ }^{1}$ Hannah T. Jordan, MD, MPH, ${ }^{1}$ \\ James E. Cone, MD, MPH, ${ }^{1}$ Mark R. Farfel, ${ }^{S c D},{ }^{1}$ and Steven D. Stellman, ${ }^{\text {PhD, }}$ MPH $^{1,2}$
}

\begin{abstract}
Background Little is known about the direction of causality among asthma, posttraumatic stress disorder (PTSD), and onset of gastroesophageal reflux symptoms (GERS) after exposure to the 9/11/2001 World Trade Center (WTC) disaster.

Methods Using data from the WTC Health Registry, we investigated the effects of early diagnosed post-9/11 asthma and PTSD on the late onset and persistence of GERS using log-binomial regression, and examined whether PTSD mediated the asthma-GERS association using structural equation modeling.

Results Of 29,406 enrollees, 23\% reported GERS at follow-up in 2011-2012. Early post-9/ 11 asthma and PTSD were each independently associated with both the persistence of GERS that was present at baseline and the development of GERS in persons without a prior history. PTSD mediated the association between early post-9/11 asthma and late-onset GERS.

Conclusions Clinicians should assess patients with post-9/11 GERS for comorbid asthma and PTSD, and plan medical care for these conditions in an integrated fashion. Am. J. Ind. Med. 59:805-814, 2016. ( $) 2016$ Wiley Periodicals, Inc.
\end{abstract}

KEY WORDS: gastroesophageal reflux; asthma; PTSD; terrorist attacks; World Trade Center

\section{INTRODUCTION}

Gastroesophageal reflux disease (GERD) is one of the most common health conditions reported among persons exposed to the 2001 World Trade Center (WTC) terrorist attacks [Prezant et al., 2002; de la Hoz et al., 2008; Li et al., 2011], and is the most common condition treated by health

\footnotetext{
${ }^{1}$ New York City Department of Health and Mental Hygiene, New York, New York

${ }^{2}$ Department of Epidemiology, Mailman School of Public Health, Columbia University, New York, New York

${ }^{*}$ Correspondence to: Jiehui Li, MBBS, MSc, New York City Department of Health and Mental Hygiene, 42-09 28th Street, Queens, NY 11101-4132.

E-mail: jli3@health.nyc.gov

Accepted 15 July 2016

DOI 10.1002/ajim.22644. Published online in Wiley Online Library (wileyonlinelibrary.com).
}

care providers under the federal WTC Health Program [WTC Health Program, 2014]. Among persons exposed to the attacks, GERD often coexists with asthma and PTSD, both of which are strongly associated with 9/11 exposure [CDC, 2002; Galea et al., 2002; Wheeler et al., 2007; DiGrande et al., 2008; Farfel et al., 2008; Brackbill et al., 2009; Neria et al., 2011; Wisnivesky et al., 2011]. Many investigators have reported on the prevalence or comorbidity of these three conditions [de la Hoz et al., 2008; Farfel et al., 2008; Brackbill et al., 2009; Debchoudhury et al., 2011; Li et al., 2011; Niles et al., 2011; Wisnivesky et al., 2011; Nair et al., 2012]; however, few have explored these interrelationships in quantitative detail, or addressed the direction of causality among the conditions themselves.

The prevalence of GERD symptoms (heartburn or acid reflux occurring at least weekly over a 12-month period) ranges from $18 \%$ to $28 \%$ in the general adult United States 
population [El-Serag et al., 2014], but is much higher, up to $59 \%$ [Havemann et al., 2007], among adults with asthma. Although the nature of this relationship remains under investigation, it is hypothesized that asthma may increase the risk for GERD via increased abdominal pressure resulting from coughing, or via diaphragmatic dysfunction resulting from pulmonary hyperinflation [Richter, 2000; Harding, 2001; Gaude, 2009]. Conversely, gastroesophageal reflux has been suggested as a potential trigger of asthma through vagal stimulation resulting from gastric fluid in the esophagus, or through micro-aspiration of gastric contents into the trachea [Harding and Richter, 1997; Harding, 2001].

Links between GERD and depression or anxiety [Jansson et al., 2007], and between GERD and PTSD [Litcher-Kelly et al., 2014], have been noted as well. It is theorized that stress may cause changes in the brain that sensitize pain receptors and thus heighten awareness of slight increases in gastric acid levels [Fass et al., 2008]. Stress may also increase gastric acid production [Johnston, 2005] or decrease the pressure of the lower esophageal sphincter (LES) [Kamolz and Velanovich, 2002].

Further complicating this picture is the welldescribed overlap between psychiatric morbidity and asthma [Goodwin et al., 2003; Lavoie et al., 2006, 2013]. Among the different types of traumatic events that can lead to the development of PTSD is the experience of lifethreatening illnesses, including asthma [Lev-Tzion et al., 2007; Chung and Wall, 2013].

Based on the above findings, we hypothesized that asthma and PTSD were each independent risk factor for subsequent onset of gastroesophageal reflux symptoms (GERS) and persistence of GERS present at baseline among persons exposed to the WTC attacks, and that the effect of having both asthma and PTSD would be greater than the effect of either condition alone. We further hypothesized that if an association between early post-9/11 asthma and lateonset GERS were present, PTSD might mediate the relationship between asthma and GERS.

We therefore investigated whether early diagnosed post9/11 asthma or PTSD were risk factors for (i) the persistence of early onset post 9-11 GERS; and (ii) the onset of new GERS approximately 10 years after $9 / 11$. We also explored PTSD as a potential mediator of the relationship between early diagnosed asthma and an increased risk of GERS.

\section{MATERIALS AND METHODS}

\section{Source and Study Population}

The World Trade Center Health Registry (WTCHR) is a longitudinal cohort study of 71,431 rescue/recovery workers and community members who were exposed to the 9/11 attacks and their aftermath. During September 2003-November 2004, registrants enrolled and completed a baseline interview (Wave 1) [Farfel et al., 2008]. All enrollees are invited to participate in periodic follow-up surveys. We used the data through Wave 3 in 2011-2012. The Registry collected 9/11related exposure information at Waves 1 and 2, and physical and mental health information at all three Waves. The Registry was approved by the institutional review board of the New York City Department of Health and Mental Hygiene.

For this analysis, we excluded enrollees aged $<18$ years on 9/11/2001; Wave 3 non-participants; interviews completed by proxies; women who were pregnant on 9/11/2001 or during the year before Wave 3; those who reported having esophageal or stomach cancer; enrollees with pre-9/11 GERS or GERD, pre-9/11 asthma; and those with missing data on GERS, asthma, or PTSD.

\section{Measures}

We defined post-9/11 GERS at baseline as a positive response to the question at Wave 1 , "Since 9/11, have you experienced heartburn, indigestion, or reflux," and a negative response to the subsequent question, "Before 9/11 did you have heartburn, indigestion or reflux?" The follow-up survey in 2011-2012, was the first time we inquired about the frequency of GERS during the preceding 12 months (never; less than once a month; about once a month; about once a week; or at least twice a week). We defined GERS at follow-up as heartburn or acid reflux occurring at least once a week. We considered enrollees with GERS both at baseline and follow-up to have persistent GERS, and those with GERS at follow-up, but not at baseline, to have late-onset GERS.

The incidence of post-9/11 asthma peaked during the first 2-3 years post-9/11 [Brackbill et al., 2009; Wisnivesky et al., 2011], and asthma diagnosed during this period is considered more likely to be 9/11-related than subsequently diagnosed asthma. We therefore examined asthma diagnosed between 9/11/2001 and 12/31/2004 as a risk factor for 9/11related GERS.

Probable PTSD was assessed at each Wave using the Stressor-Specific PTSD Checklist (PCL-S), a 17-item selfreported symptom scale which referred specifically to the events of September 11. The 17-items corresponded to Diagnostic and Statistical Manual of Mental Disorders (DSM-IV) PTSD symptoms [DSM-IV, 1994]. The PCL-S is a well-validated measure and has good temporal stability, internal consistency $(\alpha>0.75)$, test-retest reliability (correlation coefficient, $\mathrm{r}=0.66)$, and high convergent validity $(r=0.58-0.93)$ [Wilkins et al., 2011]. Enrollees were asked to rate the degree to which they were bothered by symptoms in the past 30 days (from 1 [not at all] to 5 [extremely]). Responses to the 17 items were summed, for a total score of 17-85. Probable PTSD (subsequently referred to as PTSD) 
was defined as a PCL score $\geq 44$ (overall diagnostic efficiency $=0.90$, sensitivity $=0.94$, and specificity $=0.86$ ) [Blanchard et al., 1996].

Covariates included demographics (age on 9/11, gender, race/ethnicity, household income in 2002, and education, all collected at baseline), and potential risk factors for GERS (self-reported history of clinician-diagnosed diabetes at baseline, smoking status, binge drinking and BMI at followup). BMI was categorized as obese (BMI $\geq 30$ ), overweight (BMI: 25 to $<30$ ), or normal or underweight (BMI $<25$ ). One episode of binge drinking is defined as having $\geq 5$ drinks for men and four drinks for women on a single occasion in the last 30 days preceding the follow-up survey in 2011-12 [Courtney and Polich, 2009]. Based on the number of episodes, the enrollee was defined as a non-binge drinker if he/she reported zero episodes, low-frequency 1-4 episodes, and high-frequency $>5$ episodes.

To control for potential selection bias, source of WTCHR enrollment was also included and categorized as list-identified (identified from employer, government agency, or other entity lists) or self-identified (self-referred for eligibility screening through a website or toll-free number). The WTCHR eligibility group (rescue/recovery workers vs. community members) was also considered as a potential confounder. Rescue/recovery workers included first responders, volunteers, and others who worked at the WTC site, debris loading sites, on barges, or the Staten Island landfill between 9/11/2001 and 6/30/2002. Community members were residents, children and staff in schools (pre-kindergarten-12th grade) south of Canal Street and area workers and passersby south of Chambers Street on 9/11 in lower Manhattan. Persons belonging to both groups were categorized as rescue/recovery workers [Farfel et al., 2008].

\section{Data Analysis \\ Prevalence of GERS at follow-up}

We calculated the prevalence of GERS at follow-up according to socio-demographic characteristics, BMI, rescue/recovery worker status, and comorbid asthma and PTSD status. The prevalence was further computed separately in enrollees with and without baseline GERS because we wished to study risk factors for persistent and late-onset GERS separately.

\section{Multivariable analyses}

We used log-binomial regression because GERS was common in this study (incidence $>10 \%$ ), and therefore odds ratios (OR) from logistic regression would overestimate the relative risk (RR) [Zhang and Yu, 1998;
McNutt et al., 2003]. Log-binomial regression models with log link function and binomial distribution were used [Spiegelman and Hertzmark, 2005]. We controlled for socio-demographic variables and other potentially confounding factors, including source of enrollment, age, gender, race/ethnicity, income, education, smoking, binge drinking, history of diabetes, BMI, and the WTCHR eligibility group. Because rescue/recovery workers generally experienced qualitatively different WTC exposures than exposed community members, we also stratified the multivariable analysis by the WTCHR eligibility group.

\section{Persistent GERS among enrollees with}

GERS at baseline. To examine whether comorbid asthma or PTSD were associated with persistence of GERS, we limited an analysis to enrollees with post-9/11 baseline GERS. We ran models to assess (i) whether early diagnosed post-9/11 asthma or PTSD at baseline were independently associated with persistence of GERS; and (ii) the effect of having both early post-9/11 asthma and PTSD on persistence of GERS.

Late-onset GERS among enrollees without

GERS at baseline. To assess whether early post9/11 asthma or PTSD were independently associated with late-onset GERS, we limited an analysis to enrollees without post-9/11 baseline GERS. We ran models to assess (i) the association of early post-9/11 asthma with late-onset GERS independent of PTSD at baseline; and (ii) the association of both early post-9/11 asthma and PTSD with late-onset GERS.

\section{Mediation analysis}

To explore whether the relationship between asthma and GERS was mediated by PTSD, we performed separate path analyses with structural equation modeling (SEM) [Muthén and Muthén, 2012] for rescue/recovery and for community members, restricted to those who were GERS-free at baseline. The outcome was GERS at follow-up in 2011-2012, and the exposure was early post-9/11 asthma. PCL score in 2006-2007 was used to assess whether the change in PCL scores after baseline affected the relationship between baseline asthma and GERS at follow-up. The indirect effect was the product of standardized coefficients from $a$ path (from early post-9/11 asthma to PTSD in 2006-2007) to $b$ path (from PTSD in 2006-2007 to late-onset GERS at follow-up). The Sobel test with standardized coefficients was used to test whether the indirect effect of early post-9/11 asthma on lateonset GERS via PTSD (mediator) was significantly different from zero [MacKinnon and Dwyer, 1993]. Covariates included age, gender, ethnicity, education, diabetes and PCL score at baseline, source of enrollment, smoking status, BMI and binge drinking at follow-up, and WTCHR eligibility group. 
All descriptive and multivariable analyses were performed using SAS version 9.2 (SAS Institute Inc. Cary, NC). SEM was performed using Mplus version 7.0 [Muthén and Muthén, 2012]. Statistical significance was set at a two-sided $P$-value $<0.05$. All models presented converged.

\section{RESULTS}

A total of 29,406 enrollees were included, of whom 6,085 (20.7\%) had baseline GERS and 23,321 (79.3\%) did not (Table I). Most were between the ages of 25 and 64 on September 11, $2001(\mathrm{n}=27,181 ; 92.5 \%)$, male $(63.4 \%)$, and non-Hispanic white (70.8\%). At follow-up in 2011-2012, $10.2 \%$ were current smokers, and over two-thirds (69.3\%) were overweight or obese.

\section{Prevalence of GERS at Follow-Up}

Nearly one quarter of participants $(23.3 \%, \mathrm{n}=6,855)$ reported GERS at follow-up (Table I). Among those with baseline GERS, the prevalence of GERS at follow-up was 46.5\%. Among those without baseline GERS, the prevalence of GERS at follow-up was $17.3 \%$. GERS was more prevalent among participants who were aged 25-64 years on 9/11, male, Hispanic, current smokers, overweight or obese, rescue/recovery workers, reported binge drinkers, or who had a low level of education, or lower income.

\section{Persistent GERS Among Enrollees With GERS at Baseline}

Of 6,085 enrollees with baseline GERS, persistent GERS was more prevalent among enrollees with early post9/11 asthma (61.1\% vs. $43.9 \%)$ or probable PTSD at baseline $(55.4 \%$ vs. $42.8 \%)$ than among those without these respective comorbidities (Table II). In multivariable analysis, early post-9/11 asthma (adjusted RR $1.2,95 \% \mathrm{CI}=1.1$ 1.3) and baseline PTSD (ARR 1.3, 95\% CI $=1.2-1.4)$ were each independently associated with the persistence of GERS (Table II, Model 1).

When combinations of the two comorbidities were modeled as a single composite categorical variable (early asthma, PTSD, both, or neither), enrollees with both had the highest prevalence of persistent GERS (70.6\%), followed by enrollees with asthma alone (54.5\%), PTSD alone (51.5\%), and neither condition (41.1\%) (Table II). In multivariable analysis, those with both early asthma and PTSD were 60\% more likely to have persistent GERS than those with neither condition $(95 \% \mathrm{CI}=1.5-1.7)$ (Table II, Model 2). The adjusted relative risks of having persistent GERS in rescue/recovery workers were similar to those in community members (Table II).

\section{Late-Onset GERS Among Enrollees Without GERS at Baseline}

Among 23,321 participants without baseline GERS, the prevalence of GERS at follow-up was higher among participants with early post-9/11 asthma $(29.4 \%$ vs. $16.5 \%)$ or PTSD at baseline (28.1\% vs. $16.1 \%$ ) than among those with neither condition (Table III).

After adjustment for covariates, enrollees with early post-9/11 asthma were 50\% more likely to develop late-onset GERS compared to enrollees without early post-9/11 asthma $(95 \% \mathrm{CI}=1.4-1.6)$ (Model 1, Table III). Enrollees with baseline probable PTSD were $60 \%$ more likely to develop late-onset GERS at follow-up $(95 \% \mathrm{CI}=1.5-1.7)$ (Model 1 in Table III).

Model 2 used a categorical variable reflecting the presence of early asthma, early PTSD, both, or neither. Participants with both comorbidities had a higher prevalence of late-onset GERS than did participants with neither (38.7\% vs. $15.5 \%$ ). Adjusting for covariates, enrollees with both early asthma and PTSD at baseline had a risk of late-onset GERS at follow-up 2.2 times that of those with neither condition $(95 \% \mathrm{CI}=1.9-2.6)$.

The stratification shows that rescue/recovery workers with both early asthma and PTSD at baseline had a risk of lateonset GERS at follow-up 2.6 times that of those with neither condition $(95 \% \mathrm{CI}=2.2-3.0)$ after adjustment for covariates. In contrast, community members with both early asthma and PTSD at baseline had a risk of late-onset GERS 1.7 times that of those with neither condition $(95 \% \mathrm{CI}=1.3-2.3)$.

\section{Mediation Results Among Rescue/Recovery Workers}

Among rescue/recovery workers (Fig. 1a), early post9/11 asthma was positively associated with late-onset GERS (standardized $\beta=0.212, \quad \mathrm{SE}=0.05, \quad 95 \% \mathrm{CI}=$ $0.12-0.31$, direct effect), and with PCL scores in 2006-2007 (standardized $\beta=0.298, \mathrm{SE}=0.03,95 \% \mathrm{CI}=$ $0.24-0.36$, a path). PCL score in 2006-2007 was also significantly associated with late-onset GERS (standardized $\beta=0.209, \mathrm{SE}=0.02,95 \% \mathrm{CI}=0.18-0.24, b$ path). The total indirect effect of the relationship between early asthma and late-onset GERS, mediated by PCL score, was $0.062[=0.298 \text { ( } a \text { path })^{*} 0.209$ ( $b$ path) , with significant Sobel test $(z$-value $=7.20 ; P<0.0001)$. Both direct and total indirect standardized $\beta$ s were statistically significant, indicating that early diagnosed post-9/11 asthma increased the risk of late-onset GERS directly, as well as indirectly via an increased PCL score. 
TABLE I. Prevalence of GERS at Follow-Up in 2011-2012 by Socio-Demographics and Other Selected Factors $(N=29,406)^{a}$

\begin{tabular}{|c|c|c|c|c|}
\hline & \multirow[b]{2}{*}{ No. of enrollees (\%) } & \multicolumn{3}{|c|}{ Prevalence of GERS at follow-up, \% } \\
\hline & & All $(N=29,406)$ & $\begin{array}{l}\text { Enrollees with baseline } \\
\text { GERS }(N=6,085)\end{array}$ & $\begin{array}{l}\text { Enrollees without baseline } \\
\quad \text { GERS }(\mathrm{N}=23,321)\end{array}$ \\
\hline Total & $29,406(100.0)$ & 23.3 & 46.5 & 17.3 \\
\hline \multicolumn{5}{|l|}{ Source of enrollment } \\
\hline Self-identification & $21,468(73.0)$ & 24.6 & 47.7 & 18.0 \\
\hline List-identification & 7,938 (27.0) & 19.9 & 41.9 & 15.5 \\
\hline \multicolumn{5}{|l|}{ Age on 9/11, years } \\
\hline $18-24$ & $1,520(5.2)$ & 20.4 & 45.3 & 16.1 \\
\hline $25-44$ & $15,873(54.0)$ & 23.9 & 47.6 & 17.4 \\
\hline $45-64$ & $11,308(38.5)$ & 23.2 & 45.4 & 17.5 \\
\hline$\geq 65$ & $705(2.4)$ & 17.5 & 35.7 & 14.0 \\
\hline \multicolumn{5}{|l|}{ Gender } \\
\hline Male & $18,650(63.4)$ & 24.8 & 49.1 & 18.3 \\
\hline Female & $10,756(36.6)$ & 20.6 & 41.6 & 15.5 \\
\hline \multicolumn{5}{|l|}{ Race/ethnicity } \\
\hline Non-Hispanic white & $20,823(70.8)$ & 26.5 & 48.3 & 17.6 \\
\hline Non-Hispanic black & $2,915(9.9)$ & 22.7 & 36.1 & 13.3 \\
\hline Hispanic & $3,217(10.9)$ & 37.9 & 51.0 & 22.1 \\
\hline Asian & $1,594(5.4)$ & 17.9 & 38.3 & 11.6 \\
\hline Other or unknown & $857(2.9)$ & 22.9 & 40.3 & 16.8 \\
\hline \multicolumn{5}{|l|}{ Education, 2003-2004 } \\
\hline College or above & $15,853(53.9)$ & 19.2 & 41.8 & 14.8 \\
\hline Below college & $13,436(45.7)$ & 28.1 & 49.9 & 20.5 \\
\hline \multicolumn{5}{|c|}{ Household income, 2003-2004 (\$) } \\
\hline$<50 \mathrm{k}$ & $7,249(24.7)$ & 25.2 & 47.1 & 18.1 \\
\hline 50-150k & $16,148(54.9)$ & 24.3 & 47.2 & 18.0 \\
\hline$>150 k$ & $3,377(11.5)$ & 17.1 & 40.4 & 13.7 \\
\hline \multicolumn{5}{|l|}{ Smoking history } \\
\hline Current smoker & 2,993 (10.2) & 27.2 & 47.4 & 19.7 \\
\hline Former & $9,290(31.6)$ & 24.2 & 45.1 & 18.7 \\
\hline Never & $16,521(56.2)$ & 22.0 & 46.8 & 16.0 \\
\hline \multicolumn{5}{|l|}{ Binge drinking at follow-up } \\
\hline None & $20,805(70.8)$ & 22.2 & 44.6 & 16.7 \\
\hline Low-frequency & $5,507(18.7)$ & 22.9 & 46.2 & 16.6 \\
\hline High-frequency & $2,288(7.8)$ & 33.3 & 56.6 & 24.7 \\
\hline \multicolumn{5}{|l|}{ BMI at follow-up } \\
\hline$\geq 30$ (Obese) & $8,897(30.3)$ & 28.7 & 49.5 & 21.6 \\
\hline 25 to <30 (Overweight) & $11,476(39.0)$ & 24.8 & 47.4 & 18.5 \\
\hline$<25$ (Normal/underweight) & $8,468(28.8)$ & 15.7 & 38.4 & 11.9 \\
\hline \multicolumn{5}{|l|}{ History of diabetes at enrollment } \\
\hline Yes & $1,107(3.8)$ & 24.1 & 43.3 & 18.2 \\
\hline No & 28,289 (96.2) & 23.3 & 46.6 & 17.2 \\
\hline \multicolumn{5}{|l|}{ WTCHR eligibility group } \\
\hline Rescue/recovery workers & $14,374(48.9)$ & 27.9 & 52.4 & 20.4 \\
\hline Community members & $15,032(51.1)$ & 18.9 & 39.2 & 14.4 \\
\hline
\end{tabular}

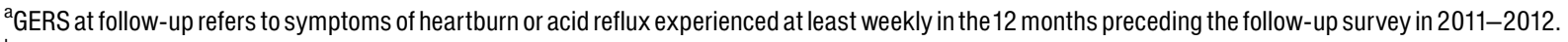
${ }^{\mathrm{b}}$ Numbers may not add up to the total due to missing data. 
TABLE II. Association of Comorbid Early Post-9/11 Asthma and Probable PTSD With Persistent GERS Among Enrollees With Post-9/11Baseline GERS in 2003-2004 ( $\mathrm{N}=6,085)$

\begin{tabular}{|c|c|c|c|c|c|c|}
\hline & \multirow[b]{2}{*}{$\begin{array}{c}\text { No. of } \\
\text { enrollees }\end{array}$} & \multirow[b]{2}{*}{$\begin{array}{c}\% \text { with persistent } \\
\text { GERS }\end{array}$} & \multicolumn{2}{|c|}{ All } & \multirow{2}{*}{ 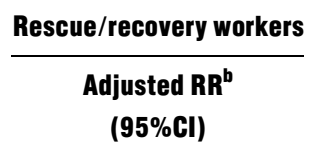 } & \multirow{2}{*}{$\begin{array}{c}\text { Community membe } \\
\text { Adjusted RR } \\
\text { (95\%CI) }\end{array}$} \\
\hline & & & $\begin{array}{l}\text { Unadjusted RR } \\
\text { (95\%CI) }\end{array}$ & $\begin{array}{l}\text { Adjusted RR }{ }^{\mathrm{a}} \\
\text { (95\%CI) }\end{array}$ & & \\
\hline \multicolumn{7}{|l|}{ Model1 } \\
\hline \multicolumn{7}{|c|}{ Early post-9/11 asthma diagnosed in 2001-04 } \\
\hline Yes & 896 & 61.1 & $1.4(1.3-1.5)$ & $1.2(1.1-1.3)$ & $1.2(1.1-1.3)$ & $1.3(1.2-1.5)$ \\
\hline No & 5,189 & 43.9 & Referent & Referent & Referent & Referent \\
\hline \multicolumn{7}{|c|}{ Early post-9/11 probable PTSD (PCL $\geq 44)$ (2003-04) } \\
\hline Yes & 1,775 & 55.4 & $1.3(1.2-1.4)$ & $1.3(1.2-1.4)$ & $1.3(1.2-1.4)$ & $1.4(1.2-1.5)$ \\
\hline No & 4,310 & 42.8 & Referent & Referent & Referent & Referent \\
\hline \multicolumn{7}{|l|}{ Model 2} \\
\hline \multicolumn{7}{|c|}{ Early post-9/11 asthma (2001-04) and PTSD (2003-04) } \\
\hline Yes (both) & 364 & 70.6 & $1.7(1.6-1.9)$ & $1.6(1.5-1.7)$ & $1.6(1.4-1.7)$ & $1.8(1.6-2.1)$ \\
\hline Asthma alone & 532 & 54.5 & $1.3(1.2-1.4)$ & $1.2(1.1-1.3)$ & $1.2(1.1-1.3)$ & $1.3(1.0-1.5)$ \\
\hline PTSD alone & 1,411 & 51.5 & $1.3(1.2-1.3)$ & $1.3(1.2-1.4)$ & $1.2(1.1-1.3)$ & $1.3(1.2-1.5)$ \\
\hline Neither & 3,778 & 41.1 & Referent & Referent & Referent & Referent \\
\hline
\end{tabular}

$\mathrm{RR}$, relative risk; $\mathrm{Cl}$, confidence interval.

${ }^{a}$ Adjusted for demographics (age, gender, Hispanic ethnicity, household income, college), source of enrollment, history of diabetes, smoking status, BMI, and binge drinking at follow-up, and WTCHR eligibility group.

${ }^{\mathrm{b}}$ Adjusted for demographics (age, gender, Hispanic ethnicity, household income, college), source of enrollment, history of diabetes, smoking status, BMI, and binge drinking at follow-up.

TABLE III. Association of Early Post-9/11 Asthma and PTSD at Baseline with Late-Onset GERS at Follow-Up in 2011-2012 Among Enrollees Without Post-9/11 Baseline GERS in 2003-2004 ( $N=23,321)$

\begin{tabular}{cccccc} 
& & \multicolumn{2}{c}{ All } & Rescue/recovery workers & Community members \\
\cline { 3 - 5 } No. of & $\%$ with persistent & Unadjusted RR & ${\text { Adjusted } \mathrm{RR}^{\mathrm{a}}}$ & Adjusted $\mathrm{RR}^{\mathrm{b}}$ & ${\text { Adjusted } \mathrm{RR}^{\mathrm{b}}(95 \% \mathrm{Cl})}^{\text {enrollees }}$ \\
\cline { 3 - 5 } & GERS & $(95 \% \mathrm{Cl})$ & $(95 \% \mathrm{Cl})$ & $(95 \% \mathrm{Cl})$ &
\end{tabular}

\begin{tabular}{|c|c|c|c|c|c|c|}
\hline \multicolumn{7}{|l|}{ Model1 } \\
\hline \multicolumn{7}{|c|}{ Early post-9/11 asthma diagnosed in 2001-04 } \\
\hline Yes & 1,352 & 29.4 & $1.8(1.6-1.9)$ & $1.5(1.4-1.6)$ & $1.5(1.4-1.7)$ & $1.5(1.3-1.8)$ \\
\hline No & 21,969 & 16.5 & Referent & Referent & Referent & Referent \\
\hline \multicolumn{7}{|c|}{ Early post-9/11 probable PTSD (PCL $\geq 44)$ (2003-04) } \\
\hline Yes & 2,245 & 28.1 & $1.7(1.6-1.9)$ & $1.6(1.5-1.7)$ & $1.7(1.6-1.9)$ & $1.5(1.3-1.7)$ \\
\hline No & 21,076 & 16.1 & Referent & Referent & Referent & Referent \\
\hline \multicolumn{7}{|l|}{ Model 2} \\
\hline \multicolumn{7}{|c|}{ Early post-9/11 asthma (2001-04) and PTSD (2003-04) } \\
\hline Yes (both) & 238 & 38.7 & $2.5(2.1-2.9)$ & $2.2(1.9-2.6)$ & $2.6(2.2-3.0)$ & $1.7(1.3-2.3)$ \\
\hline Asthma alone & 1,114 & 27.4 & $1.8(1.6-2.0)$ & $1.6(1.4-1.8)$ & $1.5(1.3-1.7)$ & $1.8(1.5-2.1)$ \\
\hline PTSD alone & 2007 & 26.9 & $1.7(1.6-1.9)$ & $1.7(1.5-1.8)$ & $1.7(1.6-2.0)$ & $1.6(1.4-1.8)$ \\
\hline Neither & 19,962 & 15.5 & Referent & Referent & Referent & Referent \\
\hline
\end{tabular}

$\mathrm{RR}$, relative risk; $\mathrm{Cl}$, confidence interval.

${ }^{\mathrm{a}}$ Adjusted for demographics (age, gender, Hispanic ethnicity, household income, college), source of enrollment, history of diabetes, smoking status, BMI, and binge drinking at follow-up, and WTCHR eligibility group.

${ }^{\mathrm{b}}$ Adjusted for demographics (age, gender, Hispanic ethnicity, household income, college), source of enrollment, history of diabetes, smoking status, BMI, and binge drinking at follow-up. 

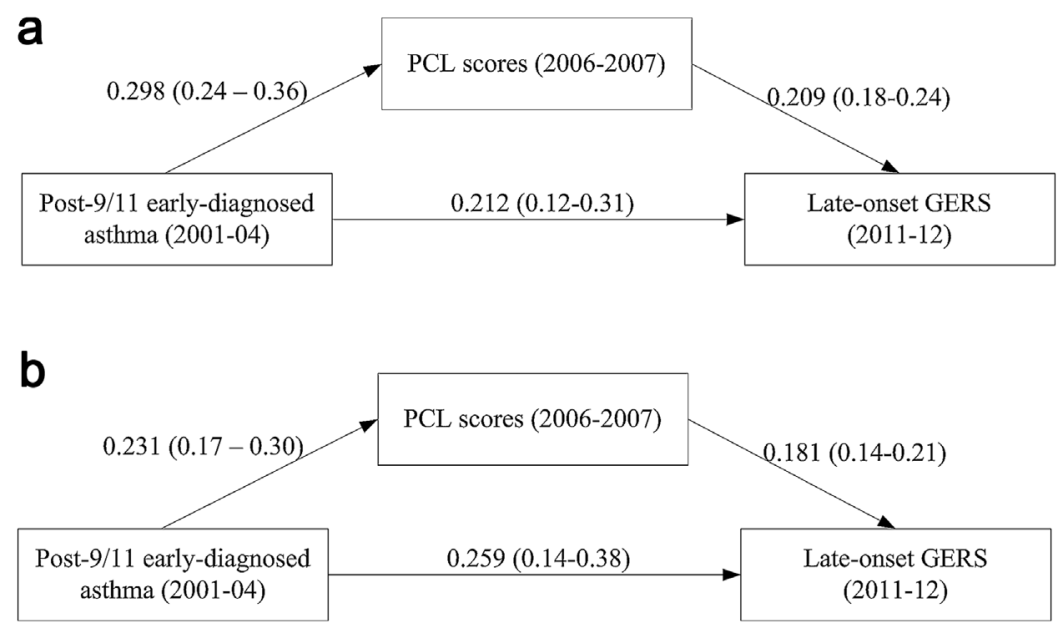

FIGURE 1. (a) Path analysis of asthma predicting late-onset GERS among rescue/recovery workers without baseline GERS with standardized regression coefficients ( $95 \%$ confidence interval) (appearing along the paths) adjusting for age, gender, Hispanic ethnicity, education level, smoking status, baseline PCL score, BMI, binge drinking, history of diabetes, and source of WTCHR enrollment. (b) Path analysis of asthma predicting late-onset GERS among community members without baseline GERS with standardized regression coefficients (95\% confidence interval) (appearing along the paths) adjusting for age, gender, Hispanic ethnicity, education level, smoking status, baseline PCL score, BMI, binge drinking, history of diabetes, and source of WTCHR enrollment.

\section{Mediation Results Among Community Members}

Among community members (Fig. 1b), early post-9/11 asthma at baseline was significantly associated with late-onset GERS at follow-up (standardized $\beta=0.259, \mathrm{SE}=0.06,95 \%$ $\mathrm{CI}=0.14-0.38$, direct effect). Early post-9/11 asthma at baseline also significantly predicted PCL score (standardized $\beta=0.231, \mathrm{SE}=0.03,95 \% \mathrm{CI}=0.17-0.30$ ) which in turn predicted late-onset GERS at follow-up (standardized $\beta=0.181, \mathrm{SE}=0.02,95 \% \mathrm{CI}=0.14-0.22)$. The total indirect effect of the relationship between early asthma and late-onset GERS, mediated by PCL score, was $0.042(=0.231 \text { [ } a \text { path }]^{*}$ $0.181[b$ path $]$ ), with a significant Sobel test (z-value $=5.86$; $P<0.0001)$.

\section{DISCUSSION}

This study of over 29,000 9/11-exposed persons followed for a 9-year period found that early diagnosed post-9/11 asthma and PTSD were each associated with the subsequent development of GERS, as well as with the persistence of GERS that were present at baseline. In addition to a direct association between early diagnosed asthma and late-onset GERS, we found an indirect association between these conditions mediated by posttraumatic stress symptoms.

GERS have long been recognized to be associated with asthma [Sontag et al., 1990; Harding et al., 2000; Harding,
2001; Ahmed and Vaezi, 2005; Havemann et al., 2007; Gaude, 2009], but there are few published studies of the directionality of this association. One study found an increased risk of GERS among patients with asthma during 3 years of follow-up of a UK general practice population [Ruigómez et al., 2005], but little effect in the opposite direction. Our finding that early diagnosed asthma was associated with late-onset GERS established a clear temporal relationship between the two conditions, adding further evidence that asthma may be a risk factor for the onset of GERS. Unfortunately, we are not able to assess the risk of asthma following frequent GERS in this study because the frequency of GERS was not queried at baseline.

Although many previous studies have suggested that PTSD is a risk factor for asthma and other respiratory symptoms after 9/11 exposure [Niles et al., 2011; Shiratori and Samuelson, 2012; Jordan et al., 2015], few assessed the direction of causality between PTSD and GERS [LitcherKelly et al., 2014]. Litcher-Kelly et al. [2014] reported that the risk of new-onset heartburn and reflux approximately 6 years after 9/11 was three times higher among participants who had PTSD 3-4 years after 9/11 than among those without PTSD. Consistent with this, we found an association between PTSD and subsequent late-onset GERS independent of asthma and other risk factors.

The relationship between early asthma and PTSD and the increased risk of subsequent GERS was further supported by the path analysis results. Early asthma was associated with late-onset GERS not only directly, but also indirectly through posttraumatic stress symptoms. Comorbidity of asthma with 
PTSD has been reported in a number of populations, including veterans [Goodwin et al., 2007], but a path by which early asthma may lead to subsequent posttraumatic stress symptoms is conjectural at present. A severe asthma attack can be a potentially life-threatening illness and perceived as such. Our study did not record specific asthma attacks, but considered new-onset asthma diagnosed within a little over 3 years after the September 11 attacks, and found a significant association in the path of asthma-posttraumatic stress symptoms path in mediational analysis for both rescue/recovery workers and community members. Identification of posttraumatic stress symptoms as a mediator may guide further investigations into a potential causal relationship among these conditions, and suggests opportunities for prevention of GERS in 9/11exposed populations and beyond.

We found that a substantial proportion of participants who first developed GERS after exposure to the 9/11 terrorist attacks continued to experience symptoms a decade later. This is consistent with findings reported from the WTC Health Program cohort, in which the cumulative incidence of gastroesophageal reflux disease increased from $5.8 \%$ at baseline to $39.3 \%$ at year 9 [Wisnivesky et al., 2011]. In the present study, $46.5 \%$ of participants with baseline GERS had persistent symptoms almost 10 years later, and persistence of GERS was highly associated with coexisting asthma and/or PTSD.

In addition to limitations inherent to the Registry's study design [Farfel et al., 2008; Brackbill et al., 2009], including the self-reported exposures and outcomes, limitations specific to this analysis should be considered when interpreting our findings. We defined GERS based on enrollee-reported heartburn or acid reflux symptoms rather than on more objective measures, such as esophageal 24-hr $\mathrm{pH}$ probe monitoring or endoscopy [Kahrilas et al., 2008]. However, frequent GERS, defined by at least weekly heartburn or reflux symptoms during a time period, has been widely used as an endpoint in previous population-based studies [Locke et al., 1997; Jung et al., 2007; Ford et al., 2013]. We did not include silent [Fass and Dickman, 2006] and atypical GERS symptoms, such as chronic cough or hoarseness of voice [Cho et al., 2005; Vaezi, 2005] in this analysis. Therefore, our findings are limited to classic or typical GERS.

Second, our estimate of the prevalence of GERS among those with comorbid asthma or PTSD may have been inflated if participants with these comorbidities had an increased probability of being diagnosed with GERD due to more frequent contact with the medical system compared to participants without these conditions. However, our questionnaire inquired about symptoms, rather than about a diagnosis of GERD; therefore, we do not believe that our findings are fully explained by possible increased health care seeking among those with comorbidities.

Third, information on the use of medications that may be associated with late-onset GERS was not available. The effect of asthma on late-onset GERS might be confounded by some asthma medications that may cause or promote GERS by reducing the lower esophageal sphincter (LES) pressure, such as bronchodilators or anticholinergic agents [Ciccaglione et al., 2001; Havemann et al., 2007]. However, it has been reported that the relationship of abnormal gastroesophageal reflux and asthma was not dependent on the use of a bronchodilator [Sontag et al., 1990]. Moreover, a large cohort study by Ruigómez et al. [2005] found no association between the use of respiratory medications in asthmatics and a subsequent diagnosis of GERD.

Lastly, although we controlled for BMI, we were not able to assess weight gain, a risk factor for GERS [Jacobson et al., 2006], because BMI was collected only at follow-up. Future surveys will collect height and weight and thus enable us to assess the relationship between BMI change and GERS.

Among the strengths of this study was sufficient study power to examine temporal associations among asthma, PTSD, and GERS in the longitudinal WTCHR cohort. We included WTC first responders as well as community members, so the results are broadly applicable to a wide range of people who survived the WTC attacks. For the path analysis, we focused on the sub-population of participants who were free of GERS at baseline and used late-onset GERS at follow-up as the end-point, thereby minimizing potential misclassification of GERS cases. We used PCL score assessed in 2006-2007 and controlled for the change in PCL and other potential risk factors for GERS, preserving a clear temporal relationship among asthma, posttraumatic stress symptoms, and GERS.

\section{CONCLUSIONS}

Comorbid asthma and PTSD played key roles in the subsequent onset of GERS, and in the persistence of baseline GERS following 9/11. Although further study of the biological mechanisms for these associations is required, the path analysis suggested that probable PTSD mediated the relationship between early diagnosed asthma and late-onset GERS. These findings raise the possibility that successful treatment of asthma and PTSD might decrease the risk of GERS onset and persistence, and thus highlight the importance of integrating medical care for physical and psychological symptoms. The potential relationship between aero-digestive disorders and mental health should be recognized in future events where survivors experience a mixture of airborne and psychological exposures [Lucchini et al., 2012].

\section{AUTHORS' CONTRIBUTIONS}

All authors made substantial contributions to the conception or design of the work; or the acquisition, 
analysis, or interpretation of data for the work; and drafted the work or revised it critically for important intellectual content; and provided final approval of the version to be published; and agreed to be accountable for all aspects of the work in ensuring that questions related to the accuracy or integrity of any part of the work are appropriately investigated and resolved.

\section{ACKNOWLEDGMENTS}

We gratefully acknowledge the participation of all Registry enrollees. We thank Drs. Carey Maslow, Charon Gwynn, James Hadler, and Ms. Sharon E. Perlman, for their valuable review of this manuscript.

\section{FUNDING}

This study was supported by Cooperative Agreement Numbers 5U50/OH009739 from NIOSH-CDC; U50/ ATU272750 from ATSDR-CDC, which included support from the NCEH-CDC; and NYC DOHMH. Its contents are solely the responsibility of the authors and do not necessarily represent the official views of NIOSH-CDC.

\section{DISCLOSURE (AUTHORS)}

The authors declare no conflicts of interest.

\section{DISCLOSURE BY AJIM EDITOR OF RECORD}

Paul Landsbergis declares that he has no competing or conflicts of interest in the review and publication decision regarding this article.

\section{DISCLAIMER}

None.

\section{REFERENCES}

Ahmed T, Vaezi MF. 2005. The role of $\mathrm{pH}$ monitoring in extraesophageal gastroesophageal reflux disease. Gastrointest Endosc Clin N Am 15:319-331.

Blanchard EB, Jones-Alexander J, Buckley TC, Forneris CA. 1996. Psychometric properties of the PTSD checklist (PCL). Behav Res Ther 34:669-673.

Brackbill RM, Hadler JL, DiGrande L, Ekenga CC, Farfel MR, Friedman S, Perlman SE, Stellman SD, Walker DJ, Wu D, et al. 2009. Asthma and posttraumatic stress symptoms 5 to 6 years following exposure to the World Trade Center terrorist attack. JAMA 302:502-516.
Centers for Disease Control and Prevention (CDC). 2002. Self-reported increase in asthma severity after the September 11 attacks on the World Trade Center-Manhattan, New York, 2001. MMWR Morb Mortal Wkly Rep 51:781-784.

Ciccaglione AF, Grossi L, Cappello G, Malatesta MG, Ferri A, Toracchio S, Marzio L. 2001. Effect of hyoscine N-butylbromide on gastroesophageal reflux in normal subjects and patients with gastroesophageal reflux disease. Am J Gastroenterol 96(8):2306-2311.

Cho YS, Choi MG, Jeong JJ, Chung WC, Lee IS, Kim SW, Han SW, Choi KY, Chung IS. 2005. Prevalence and clinical spectrum of gastroesophageal reflux: A population-based study in Asan-si, Korea. Am J Gastroenterol 100:747-753.

Courtney KE, Polich J. 2009. Binge drinking in young adults: Data, definitions, and determinants. Psychol Bull 135(1):142-156.

Chung MC, Wall N. 2013. Alexithymia and posttraumatic stress disorder following asthma attack. Psychiatr Q 84:287-302.

Debchoudhury I, Welch AE, Fairclough MA, Cone JE, Brackbill RM, Stellman SD, Farfel MR. 2011. Comparison of health outcomes among affiliated and lay disaster volunteers enrolled in the World Trade Center Health Registry. Prev Med 53:359-363.

de la Hoz RE, Shohet MR, Chasan R, Bienenfeld LA, Afilaka AA, Levin SM, Herbert R. 2008. Occupational toxicant inhalation injury: The World Trade Center (WTC) experience. Int Arch Occup Environ Health 81:479-485.

DiGrande L, Perrin MA, Thorpe LE, Thalji L, Murphy J, Wu D, Farfel M, Brackbill RM. 2008. Posttraumatic stress symptoms, PTSD, and risk factors among lower Manhattan residents 2-3 years after the September 11, 2001 terrorist attacks. J Trauma Stress 21:264-273.

DSM-IV, A. Diagnostic and statistic manual of mental disorders. American Psychiatric Association: Washington, DC, 1994.

El-Serag HB, Sweet S, Winchester CC, Dent J. 2014. Update on the epidemiology of gastro-oesophageal reflux disease: A systematic review. Gut 63:871-880.

Farfel M, DiGrande L, Brackbill R, Prann A, Cone J, Friedman S, Walker DJ, Pezeshki G, Thomas P, Galea S, et al. 2008. An overview of 9/11 experiences and respiratory and mental health conditions among World Trade Center Health Registry enrollees. J Urban Health 85:880-909.

Fass R, Dickman R. 2006. Clinical consequences of silent gastroesophageal reflux disease. Curr Gastroenterol Rep 8:195-201.

Fass R, Naliboff BD, Fass SS, Peleg N, Wendel C, Malagon IB, Mayer EA. 2008. The effect of auditory stress on perception of intraesophageal acid in patients with gastroesophageal reflux disease. Gastroenterology 134:696-705.

Ford AC, Forman D, Bailey AG, Axon AT, Moayyedi P. 2013. The natural history of gastro-oesophageal reflux symptoms in the community and its effects on survival: A longitudinal 10-year follow-up study. Aliment Pharmacol Ther 37:323-331.

Galea S, Ahern J, Resnick H, Kilpatrick D, Bucuvalas M, Gold J, Vlahov D. 2002. Psychological sequelae of the September 11 terrorist attacks in New York City. N Engl J Med 346:982-987.

Gaude GS. 2009. Pulmonary manifestations of gastroesophageal reflux disease. Ann Thorac Med 4:115-123.

Goodwin RD, Olfson M, Shea S, Lantigua RA, Carrasquilo O, Gameroff MJ, Weissman MM. 2003. Asthma and mental disorders in primary care. Gen Hosp Psychiatry 25:479-483.

Goodwin RD, Fischer ME, Goldberg J. 2007. A twin study of posttraumatic stress disorder symptoms and asthma. Am J Respir Crit Care Med 176(10):983-987.

Harding SM, Richter JE. 1997. The role of gastroesophageal reflux in chronic cough and asthma. Chest 111:1389-1402. 
Harding SM, Guzzo MR, Richter JE. 2000. The prevalence of gastroesophageal reflux in asthma patients without reflux symptoms. Am J Respir Crit Care Med 162:34-39.

Harding SM. 2001. Gastroesophageal reflux, asthma, and mechanisms of interaction. Am J Med 111(Suppl 8A):8S-12S

Havemann BD, Henderson CA, El-Serag HB. 2007. The association between gastro-oesophageal reflux disease and asthma: A systematic review. Gut 56:1654-1664.

Jacobson BC, Somers SC, Fuchs CS, Kelly CP, Camargo CA Jr. 2006. Body-mass index and symptoms of gastroesophageal reflux in women. N Engl J Med 354:2340-2348.

Jansson C, Nordenstedt H, Wallander MA, Johansson S, Johnsen R, Hveem K, Lagergren J. 2007. Severe gastro-oesophageal reflux symptoms in relation to anxiety, depression and coping in a population-based study. Aliment Pharmacol Ther 26:683-691.

Johnston BT. 2005. Stress and heartburn. J Psychosom Res 59:425-426.

Jordan HT, Stellman SD, Reibman J, Farfel MR, Brackbill RM, Friedman SM, Li J, Cone JE. 2015. Factors associated with poor control of 9/11-related asthma 10-11 years after the 2001 World Trade Center terrorist attacks. J Asthma 52:630-637.

Jung HK, Halder S, McNally M, Locke GR 3rd, Schleck CD Zinsmeister AR, Talley NJ. 2007. Overlap of gastro-oesophageal reflux disease and irritable bowel syndrome: Prevalence and risk factors in the general population. Aliment Pharmacol Ther 26:453-461.

Kahrilas PJ, Shaheen NJ, Vaezi MF, Hiltz SW, Black E, Modlin IM, Johnson SP, Allen J, Brill JV; American Gastroenterological Association. 2008. American Gastroenterological Association Medical Position Statement on the management of gastroesophageal reflux disease. Gastroenterology 135:1383-1391, 1391.e1-5.

Kamolz T, Velanovich V. 2002. Psychological and emotional aspects of gastroesophageal reflux disease. Dis Esophagus 15:199-203.

Lavoie KL, Bacon SL, Barone S, Cartier A, Ditto B, Labrecque M 2006. What is worse for asthma control and quality of life: Depressive disorders, anxiety disorders, or both? Chest 130:1039-1047.

Lavoie KL, Joseph M, Favreau H, Lemiere C, Labrecque M, Cartier A, Malo JL, Gautrin D, Bacon SL. 2013. Prevalence of psychiatric disorders among patients investigated for occupational asthma: An overlooked differential diagnosis? Am J Respir Crit Care Med 187:926-932.

Lev-Tzion R, Friedman T, Shochat T, Gazala E, Wohl Y. 2007. Asthma and psychiatric disorders in male army recruits and soldiers. Isr Med Assoc J 9:361-364.

Li J, Brackbill RM, Stellman SD, Farfel MR, Miller-Archie SA, Friedman S, Walker DJ, Thorpe LE, Cone J. 2011. Gastroesophageal reflux symptoms and comorbid asthma and posttraumatic stress disorder following the 9/11 terrorist attacks on World Trade Center in New York City. Am J Gastroenterol 106:1933-1941.

Litcher-Kelly L, Lam Y, Broihier JA, Brand DL, Banker SV, Kotov R, Bromet E, Bucobo JC, Shaw RD, Luft BJ. 2014. Longitudinal study of the impact of psychological distress symptoms on new-onset upper gastrointestinal symptoms in world trade center responders. Psychosom Med 76:686-693.

Locke GR 3rd, Talley NJ, Fett SL, Zinsmeister AR, Melton LJ 3rd. 1997. Prevalence and clinical spectrum of gastroesophageal reflux: A population-based study in Olmsted County, Minnesota. Gastroenterology 112:1448-1456.

Lucchini RG, Crane MA, Crowley L, Globina Y, Milek DJ, Boffetta P, Landrigan PJ. 2012. The World Trade Center health surveillance program: Results of the first 10 years and implications for prevention. G Ital Med Lav Ergon 34(3 Suppl):529-533.

MacKinnon DP, Dwyer JH. 1993. Estimating mediated effects in prevention studies. Eval Rev 17:144-158.

McNutt LA, Wu C, Xue X, Hafner JP. 2003. Estimating the relative risk in cohort studies and clinical trials of common outcomes. Am J Epidemiol 157:940-943.

Muthén LK, Muthén BO. 1998-2012. Mplus user's guide, Seventh Edition. Los Angeles, CA: Muthén \& Muthén.

Nair HP, Ekenga CC, Cone JE, Brackbill RM, Farfel MR, Stellman SD. 2012. Co-occurring lower respiratory symptoms and posttraumatic stress disorder 5 to 6 years after the World Trade Center terrorist attack. Am J Public Health 102:1964-1973.

Neria Y, DiGrande L, Adams BG. 2011. Posttraumatic stress disorder following the September 11, 2001, terrorist attacks: A review of the literature among highly exposed populations. Am Psychol 66:429-446.

Niles JK, Webber MP, Gustave J, Cohen HW, Zeig-Owens R, Kelly KJ, Glass L, Prezant DJ. 2011. Comorbid trends in World Trade Center cough syndrome and probable posttraumatic stress disorder in firefighters. Chest 140:1146-1154.

Prezant DJ, Weiden M, Banauch GI, McGuinness G, Rom WN, Aldrich TK, Kelly KJ. 2002. Cough and bronchial responsiveness in firefighters at the World Trade Center site. N Engl J Med 347:806-815.

Richter JE. 2000. Gastroesophageal reflux disease and asthma: The two are directly related. Am J Med 108(Suppl 4a):153S-158S.

Ruigómez A, Rodríguez LA, Wallander MA, Johansson S, Thomas M, Price D. 2005. Gastroesophageal reflux disease and asthma: A longitudinal study in UK general practice. Chest 128:85-93.

Shiratori Y, Samuelson KW. 2012. Relationship between posttraumatic stress disorder and asthma among New York area residents exposed to the World Trade Center disaster. J Psychosom Res 73:122-125.

Spiegelman D, Hertzmark E. 2005. Easy SAS calculations for risk or prevalence ratios and differences. Am J Epidemiol 162:199-200.

Sontag SJ, O'Connell S, Khandelwal S, Miller T, Nemchausky B, Schnell TG, Serlovsky R. 1990. Most asthmatics have gastroesophageal reflux with or without bronchodilator therapy. Gastroenterology 99:613-620.

Vaezi MF. 2005. Atypical manifestations of gastroesophageal reflux disease. MedGenMed 7:25-26.

Wheeler K, McKelvey W, Thorpe L, Perrin M, Cone J, Kass D, Farfel M, Thomas P, Brackbill R. 2007. Asthma diagnosed after 11 September 2001 among rescue and recovery workers: Findings from the World Trade Center Health Registry. Environ Health Perspect $115: 1584-1590$

Wilkins KC, Lang AJ, Norman SB. 2011. Synthesis of the psychometric properties of the PTSD Checklist (PCL) military, civilian, and specific versions. Depress Anxiety 28(7):596-606.

Wisnivesky JP, Teitelbaum SL, Todd AC, Boffetta P, Crane M, Crowley L, de la Hoz RE, Dellenbaugh C, Harrison D, Herbert R, et al. 2011. Persistence of multiple illnesses in World Trade Center rescue and recovery workers: A cohort study. Lancet 378:888-897.

WTC Health Program-Program Update STAC_February 14, 2014 Meeting. Available: http://www.cdc.gov/wtc/pdfs/20140214progupd atetostac.pdf [accessed 19 April 2016].

Zhang J, Yu KF. 1998. What's the Relative Risk? A method of correcting the odds ratio in cohort studies of common outcomes. JAMA 280:1690-1691. 